Presented at the May 22-26, 2011, World Environmental and Water Resources Congress in Palm Springs, California. http://www.itrc.org/papers/tccadoppler.htm ITRC Paper No. P 11-012

\title{
Implementation and Field Calibration Pipeline Doppler Meters in Northern California
} Stuart Styles ${ }^{1}$, Lynn Groundwater ${ }^{2}$, and Jim Weathers ${ }^{3}$

${ }^{1}$ Irrigation Training and Research Center, BioResource and Ag Engineering, Cal Poly State University, 1 Grand Avenue, San Luis Obispo, California, 93407; PH (805)756-2434; FAX (805)756-2433; email: sstyles@calpoly.edu

${ }^{2}$ Irrigation Training and Research Center, BioResource and Ag Engineering, Cal Poly State University, 1 Grand Avenue, San Luis Obispo, California, 93407; PH (805)756-2434; FAX (805)756-2433; email: lgroundw@calpoly.edu

${ }^{3}$ Tehama Colusa Canal Company, 5513 State Highway 162 Willows, CA 95988

\section{ABSTRACT}

The Tehama-Colusa Canal Authority (TCCA) has been using SonTek Doppler flow meters at approximately 30 installations for about 3 years. TCCA is located in northern California with its headquarters in Willows. The Cal Poly ITRC compared the accuracy of the flow measurement readings from the new Doppler flow meters to the venturi meters that were installed by the US Bureau of Reclamation (USBR). The venturis were used as the historical standard for flow measurement for TCCA. TCCA has opted to move away from the existing technology for a variety of reasons, especially due to the issue concerning access requirements for an enclosed space. TCCA has opted to use the Doppler meter as the replacement. In past studies, ITRC has used the R-Squared statistic to set the minimum number of data points for calibration. This paper evaluates the technique used by USGS to report the calibration of a meter.

\section{BACKGROUND}

The Tehama Colusa Canal System diverts water from the Sacramento River for use by various water districts across the region. The canal system is owned by the U.S. Bureau of Reclamation (USBR) and operated by the Tehama Colusa Canal Authority (TCCA). The dam at Red Bluff is owned and operated by the USBR. Within this arrangement exists a network of release structures and pumps that frequently result in complex flow conditions in the canals and pipes that deliver water to districts supplied by the system. Because of these dynamic conditions, modernized flow instrumentation is necessary to accurately measure the flow rate so that the total water flow rate and volume numbers are correct (Ward et al. 2007).

The flow rates and volumes are measured twice for recording purposes: once by the Bureau of Reclamation at the head of the Tehama Colusa Canal and once by the TCCA at the laterals. The TCCA volume numbers need to be within $10 \%$ of the volume recorded by the Bureau. TCCA currently uses a Badger meter in combination with a venturi to measure the flow rate and volume. The Badger flow meter is currently used to bill consumers, but TCCA wants to switch over to a new technology for billing (Ward et al. 2007).

Venturis, seen in Figure 1, have been used for a number of years by several of the projects originally constructed and maintained by the USBR. However, for several reasons, they are currently being evaluated for replacement by TCCA:

1. Enclosed space access. The venturis are located in "pits." These areas are now classified as confined spaces and subject to OSHA requirements for a confined workplace. OSHA standards require at least two staff people to be in attendance when each measurement is taken. 
2. Air in the lines. There are two problems with having air in the lines:

a. Air takes up space. If the air represents $4 \%$ of the area in the pipeline as it passes through a meter, then the meter will be over-reporting the flow rate by $4 \%$.

b. Air can get into the feed lines that measure the pressure differential at the venturi. This can lead to long-term errors in the data reported by the meter.

3. Turbulence. The venturi meter can be installed in the pipeline in conditions that are less than ideal due to space constraints. The venturi can be located close to the pumps and in close proximity with elbows. This may cause excessive turbulence at the entrance to the venturi.

4. Availability of parts. TCCA has identified the replacement cost and availability of parts for the Badger Recorder as an issue for future consideration.

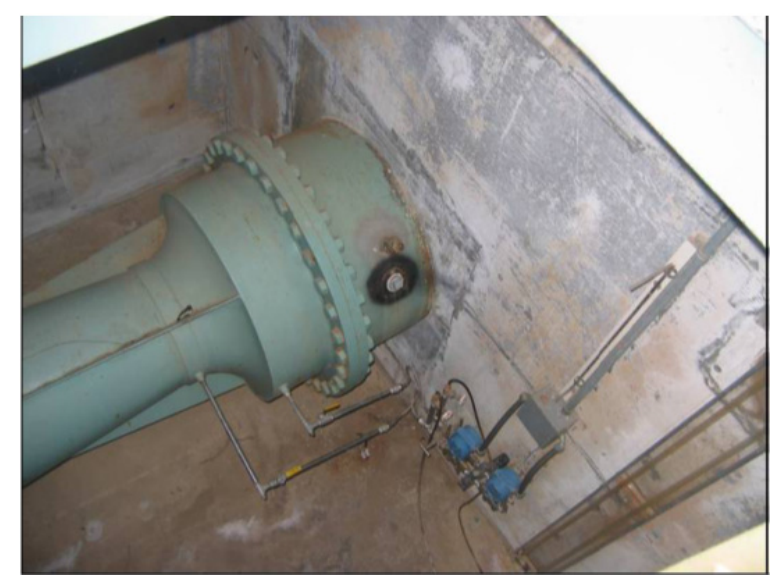

Figure 1. TCCA venturi meter.

Note the meter is located about 30 feet below the ground surface.

TCCA has opted to use a new technology: Doppler flow meters located in the pipeline. The device selected is the SonTek Argonaut SW. These devices have been used successfully in several irrigation districts in California.

TCCA currently calibrates flow measured by the SonTek SW using the venturi meters, which are recorded by logging equipment by Badger Instruments. As indicated previously, the Badgers are failing due to age, and replacement parts are increasingly unavailable. While a data review of the venturi meters showed the instantaneous values to be very good, the venturi showed some discrepancies under the constant flow tests.

Until 2006, the venturi has been the primary measurement device of the TCCA and the expected flow rate accuracy was within $\pm 5 \%$ of the true instantaneous flow rate. This level of accuracy has been verified by TCCA staff through numerous field checks of the measured flow rate compared to instantaneous pitot meter readings.

\section{SONTEK INSTALLATION/CALIBRATION}

Hydroacoustic flow meters, such as the SonTek SW, are high-precision instruments that very accurately measure the velocity of water in the section of flow being sampled. The water velocity measured by hydroacoustic flow meters represents a sampled portion of the flow that can be used as an "index" for the actual mean water velocity. Acoustic flow meters are a new technology that are well suited for difficult flow metering sites where traditional discharge measurement structures (weirs and flumes) are not practical (e.g., at sites with backwater problems caused by 
downstream gates and tides). These instruments combine, in a small package, the capability to measure depth, velocity, and temperature, and using this information calculate and log a discharge. Like all electronic systems, acoustic flow meters require periodic maintenance that will vary from site to site (Vermeyen 2000).

A hydroacoustic flow meter provides remote velocity sampling and integrated flow measurement based on the physical principle call the Doppler shift. The sensors can either project a continuous or pulsed beam of acoustic signals at angles above the horizontal position of the sensor. Flow velocity is calculated by averaging the measured variations in sound frequency reflected back from particles in the water. Depth is measured with a ceramic-based pressure transducer integrally mounted in a surface mount velocity sensor and the device calculates the flow rate (ITRC 2005).

The SonTek-SW provides a vertically integrated velocity measurement. This measurement configuration provides an improved index velocity in complicated flow regimes, including highly variable water levels and stratified flow. It also provides improved performance for theoretical flow calculations, which are important in smaller channels where an index calibration may not be practical. The sensor is also intended for use in pipes with diameters from 0.3 to $5 \mathrm{~m}$ (Huhta and Ward 2003).

The installation of the new SonTek SW flow meter followed guidelines recommended by the ITRC. Figure 2 shows the new installation. The ITRC guidelines include:

- The location of the device must be at least ten times the average canal width or pipeline diameter away from bends or turbulences to ensure a good, even velocity distribution.

- The device must be located in a pipeline or a concrete-lined section of a canal that has been properly surveyed. The concrete section provides a stable stage-area rating.

- The device must be installed on a secure mounting bracket for easy removal of the sensor for maintenance. Even more important, the mounting bracket must be designed so that when the device is placed back into the canal, it returns to the exact same location and horizontal angle.

- A trash deflector should be installed around the device to prevent trash, algae, and weeds from collecting on or around the sensors.

- A calibration procedure, such as the Flow Rate Indexing Procedure (QIP), must be completed on most Doppler installations.

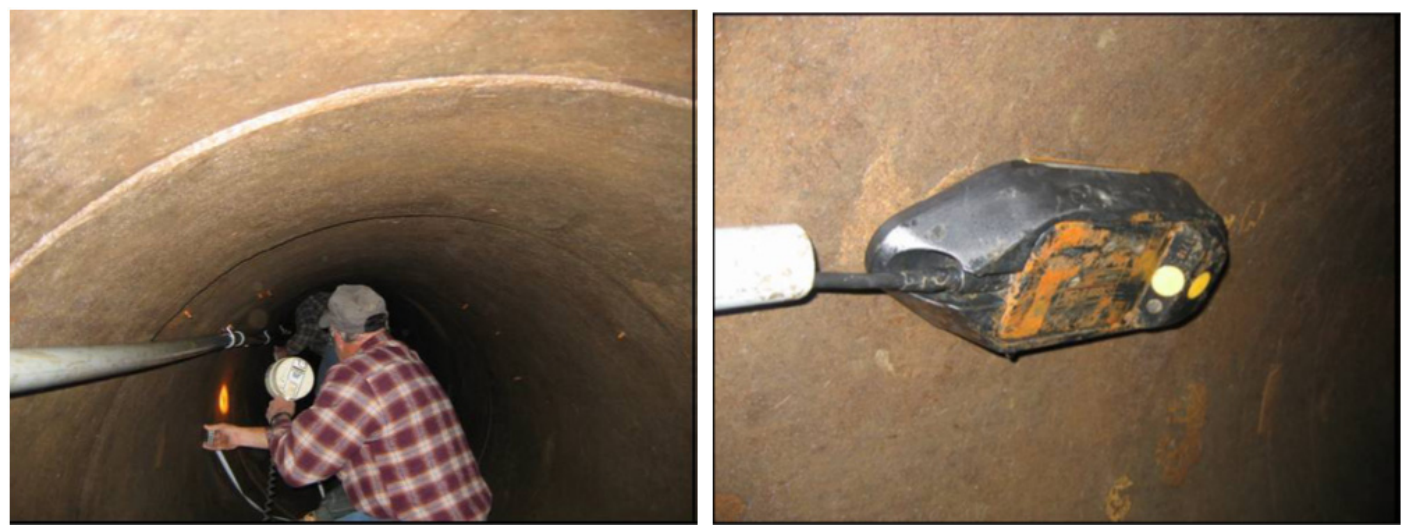

Figure 2. Installation of SonTek Meter 
A calibration procedure [sometimes referred to as velocity indexing but herein termed the flow rate indexing procedure (QIP)] has been developed to address this problem of converting the sample velocity into a true average channel velocity. This procedure has been incorporated into the software run by many Doppler devices. At least 10 individual flow and depth conditions are recommended for the QIP. It is time-consuming and logistically challenging to obtain calibration data over a wide range of flow conditions (Howes et al. 2010).

The flow rate is computed internally by devices such as the Argonaut SW flow meter by firmware in the instrument using a programmed stage-area rating and the index water velocity $(\mathrm{Q}$ $=\mathrm{V} \times \mathrm{A})$. The user can input an indexing equation into the unit with the deployment software based on the results of the QIP process. The QIP process developed by ITRC is described in detail in the Non-Standard Structure Flow Measurement Evaluation using the Flow Rate Indexing Procedure - QIP, technical report (September 2006).

In QIP applications, the measured velocity is sampled and recorded in programmed time intervals concurrently by both the device being calibrated (e.g., an Argonaut SW upstream of the pumps) and a second device that produces a very accurate discharge measurement such as a venturi meter downstream of the pumps. Mean velocities can also be obtained from other techniques such as pitot tube measurements, as long as the time periods are the same (Styles et al. 2006).

\section{RESULTS}

The resulting data for multiple pairs of mean velocity and index velocity collected over a range of flows are analyzed using regression techniques, with and without multi-parameter ratings to account for the effect of stage. The resulting equation of the index velocity rating is necessary for using the internal flow computational feature on hydroacoustic flow meters or for postprocessing data from temporary deployments.

The goal of this project was to check the accuracy of the readings from the SonTek flow meters compared to the venturi meters that are currently used. Many irrigation districts and other water agencies are moving towards Doppler flow meters for these types of sites to minimize restrictions associated with confined and enclosed space access. However, the calibration of the units can take some time due to a discussion on the minimum number of data points required to adequately calibrate a field site.

Most devices measure flow rate indirectly. Usually, they actually measure velocity or a hydraulic head of the device first. Then formulas, tables, or computer routines are used to solve for the flow rate. When the velocity method is used, the flow rate is based on the equation $\mathrm{Q}$ (flow rate) $=$ Velocity $\times$ Area, where the velocity is measured by the device and the area is the known cross-sectional area of the measuring point.

\section{Statistical Calibration Discussion}

After reviewing the literature it was found that the United States Geological Survey (USGS) uses 1 standard deviation to describe measurement sites and a simple rating to rate the site (Sauer and Meyer, 1992). In past studies, ITRC has used the R-Squared statistic to set the minimum number of data points. Table 1 shows the site rating range using the USGS statistical calculations to evaluate the minimum number of points required. 


\section{Table 1. Statistical evaluation of the TCCA laterals}

USGS - 1 Standard Deviation

"Excellent" means $\leq 2 \%$

"Good" means $\leq 5 \%$

"Fair" means $\leq 8 \%$

"Poor" means $\geq 8 \%$

Table 2 shows the results from TCCA laterals. Note that although R-Squared is considered high for many of the examples, more data points are generally encouraged to improve the reporting of the accuracy and to regularly verify the meters are all working properly. Also note that the field data does not compare well to laboratory data. This is to be expected since the field conditions are not hydraulically ideal. The recommendation from the ITRC is to have 10 calibration points. After 10 points have been found, the USGS rating system for the quality of calibration from a site can be done using the USGS rating system.

Table 2. Summary of the results from TCCA laterals

\begin{tabular}{|l|c|c|c|}
\hline Site & Std Dev & R-Squared & USGS Rating \\
\hline CCWD 5- 10 points & $3 \%$ & 1.00 & \\
\hline CCWD 5 -20 points & $9 \%$ & 0.99 & \\
\hline CCWD 5- 28 points & $8 \%$ & 0.99 & Fair \\
\hline & & & \\
\hline CCWD 7A- 10 points & $5 \%$ & 0.99 & \\
\hline CCWD 7A- 11 points & $5 \%$ & 1.00 & Good \\
\hline & & & \\
\hline DWD 3- 4 points & $5 \%$ & 0.97 & \\
\hline DWD 3- 10 points & $10 \%$ & 0.98 & \\
\hline DWD 3- 14 points & $9 \%$ & 0.99 & Poor \\
\hline & & & \\
\hline DWD 4- 10 points & $30 \%$ & 0.76 & Poor \\
\hline DWD 4- 11 points & $28 \%$ & 0.83 & \\
\hline & & & Fair \\
\hline WWD 5- 10 points & $7 \%$ & 1.00 & \\
\hline WWD 5- 11 points & $7 \%$ & 1.00 & \\
\hline & & & Fair \\
\hline WWD 7- 10 points & $8 \%$ & 0.98 & \\
\hline WWD 7- 18 points & $6 \%$ & 0.98 & \\
\hline & & & \\
\hline WWD 8- 10 points & $7 \%$ & 0.99 & \\
\hline WWD 8- 14 points & $8 \%$ & 0.99 & \\
\hline & & & \\
\hline WWD 9B- 10 points & $11 \%$ & 0.98 & \\
\hline WWD 9B- 12 points & $10 \%$ & 0.97 & \\
\hline
\end{tabular}

\section{CONCLUSION}

The SonTek SW flow meter will provide a more reliable flow measurement readings over the water season and will be a good replacement for the older technology when it has been fully calibrated. The venturi meter is still an accurate device and can be used to check the calibration of the SonTek SW flow meter. The venturi is probably the best choice to calibrate the SonTek unit because it is best for taking instantaneous flow measurements.

\section{REFERENCES}

Howes D., Burt C.M., and Sanders B.F. (2010). "Subcritical Contraction for Improved OpenChannel Flow Measurement Accuracy with an Upward-Looking ADVM.” J. Irrig. Drain. Eng., 136(9), 617-626. 
Huhta, C., and Ward, C. (2003). "Flow measurements using an upwardlooking Argonaut-SW Doppler current meter." Proc., IEEE/OES $7^{\text {th }}$ Working Conf. on Current Measurement Technology, San Diego, 35- 39.

Irrigation Training and Research Center (ITRC). (2005). Hydroacoustic meters. Irrigation Training and Research Center, California Polytechnic State Univ., San Luis Obispo, Calif.

Sauer, V.B., and Meyer, R.W. (1992). "Determination of error in individual discharge measurements.” USGS Open-File Rep. No. 92-144, U.S. Geological Survey, Norcross, $\mathrm{Ga}$.

Styles, S. W., Busch, B., Howes, D., and Cardenas, M. (2006). "Nonstandard structure flow measurement evaluation using the flow rate indexing procedure-QIP." $R$ 06-003, Irrigation Training and Research Center, California Polytechnic State Univ., San Luis Obispo, Calif. http://www.itrc.org/reports/qip/r06003.pdf.

Vermeyen, T. B. (2000). “A laboratory evaluation of Unidata's Starflow Doppler flowmeter and MGD technologies' acoustic Doppler flowmeter.” Proc., Joint Conf. on Water Resource Engineering and Water Resources Planning and Management, Minneapolis, ASCE, 318.

Ward, C.J., Kibby K., Nauman, R. (2007). "Upgrading the Flow Measurement System at the Tehama Colusa Canal Authority." http://www.hydroscientificwest.com/pdfs/TCCA.pdf 